\title{
Morphological alterations of exogenous surfactant inhibited by meconium can be prevented by dextran Matthias Ochs*1,2, Markus Schüttler ${ }^{2}$, Guido Stichtenoth ${ }^{3}$ and Egbert Herting 3
}

Address: ${ }^{1}$ Institute of Anatomy, Experimental Morphology, University of Bern, Baltzerstrasse 2, CH-3012 Bern, Switzerland, ${ }^{2}$ Department of Anatomy, Division of Electron Microscopy, University of Göttingen, Kreuzbergring 36, D-37075 Göttingen, Germany and ${ }^{3}$ Department of Pediatrics, University of Lübeck, Ratzeburger Allee 160, D-23538 Lübeck, Germany

Email: Matthias Ochs* - ochs@ana.unibe.ch; Markus Schüttler - m.schuettler@gmx.de; Guido Stichtenoth - stichtenoth@paedia.ukl.muluebeck.de; Egbert Herting - herting@paedia.ukl.mu-luebeck.de

* Corresponding author

Published: 06 June 2006

Respiratory Research 2006, 7:86 doi:10.1 |86/| 465-992/-7-86

This article is available from: http://respiratory-research.com/content/7/I/86

(c) 2006 Ochs et al; licensee BioMed Central Ltd.

This is an Open Access article distributed under the terms of the Creative Commons Attribution License (http://creativecommons.org/licenses/by/2.0), which permits unrestricted use, distribution, and reproduction in any medium, provided the original work is properly cited.
Received: 23 March 2006

Accepted: 06 June 2006

\begin{abstract}
Background: Surfactant dysfunction due to inhibition is involved in the pathophysiology of meconium aspiration syndrome. Dextran addition has been shown to reverse exogenous surfactant inactivation by meconium, but the precise mechanisms and the morphological correlate of this effect are yet unknown. Morphological surfactant analysis by transmission electron microscopy (TEM) and stereology allows the differentiation of active (large aggregates $=$ LA) and inactive (small aggregates $=\mathrm{SA}$ ) subtypes.

Methods: To determine the in vitro effects of meconium and dextran addition on the morphology of a modified porcine natural surfactant (Curosurf), Curosurf samples were either incubated alone or together with meconium or with meconium and dextran, fixed and processed for TEM. Volume fractions of surfactant subtypes [lamellar body-like forms (LBL), multilamellar vesicles (MV), unilamellar vesicles (UV)] were determined stereologically.

Results: All preparations contained LBL and MV (corresponding to LA) as well as UV (corresponding to SA). The volume fraction of UV increased with addition of meconium and decreased with further addition of dextran. Correspondingly, the UV/(LBL+MV) ratio (resembling the SA/LA ratio) increased when meconium was added and decreased when dextran was added to the surfactant-meconium mixture.

Conclusion: Meconium causes alterations in the ultrastructural composition of Curosurf that can be visualized and analyzed by TEM and stereology. These alterations resemble an increase in the SA/LA ratio and are paralleled by an increase in minimum surface tension. Dextran prevents these effects and may therefore be a useful additive to exogenous surfactant preparations to preserve their structural and functional integrity, thereby improving their resistance to inactivation.
\end{abstract}

\section{Background}

The surfactant system of the lung prevents alveolar col- lapse by reducing alveolar surface tension. Growing evidence suggests that certain surfactant components also 
have immunomodulatory functions. Surfactant, synthesized and secreted by type II alveolar epithelial cells, is a complex mixture of lipids, mainly saturated phospholipids, and proteins, among them the surfactant apoproteins SP-A, -B, -C and -D [1]. The two hydrophilic, large molecular weight surfactant apoproteins SP-A and SP-D are lost during extraction with organic solvents used in the production of the commercially available surfactant preparations of bovine or porcine origin. The glycoproteins SP-A and SP-D are members of the collectin family and seem to "orchestrate the lung's immune response" [2,3]. In contrast, the hydrophobic surfactant proteins SP-B and SP-C are contained in natural modified surfactants for clinical use. SP-B and SP-C are essential for the biophysical activity of surfactant preparations $[4,5]$.

Intraalveolar surfactant is present in different morphological forms which, according to current models, correspond to different stages within surfactant metabolism [6]. Surfactant material is secreted by type II cells as lamellar bodies. Within the hypophase of the alveolar lining layer, lamellar body-like forms undergo transformation into tubular myelin figures when SP-A is added to their outer lamellae [7]. Tubular myelin is thought to be the precursor of material that is inserted into the surface film. "Spent" surfactant is found in the hypophase as unilamellar vesicles and can be taken up by type II cells. After differential centrifugation of intraalveolar surfactant material obtained by bronchoalveolar lavage, surface active large aggregates (LA), largely corresponding to lamellar body-like forms, tubular myelin and multilamellar vesicles, and inactive small aggregates (SA), largely corresponding to unilamellar vesicles, can be distinguished [8-10].

Several studies indicate that dysfunction of pulmonary surfactant due to inhibition plays a key role in the pathophysiology of meconium aspiration syndrome [11-15]. Thus, there is a rationale for exogenous surfactant therapy in neonates with severe respiratory failure due to meconium aspiration [16-21]. In vitro, meconium inhibits exogenous surfactant preparations in a dose-dependent manner [22] and alters exogenous surfactant morphology [23]. The addition of nonionic polymers like dextran has been shown to reverse the inactivation of exogenous surfactant by meconium in vitro [24-26]. This and other in vitro and in vivo findings [27-30] have led to the concept that surfactant inactivation in various forms of acute lung injury may be overcome with the help of nonionic polymers [31]. However, the precise mechanisms and the morphological correlate of these effects are yet unknown.

Inactivation of intraalveolar surfactant in acute lung injury and related conditions includes increased conversion of surface active LA to SA with poor surface activity.
The SA/LA ratio of surfactant material obtained by bronchoalveolar lavage is therefore used to assess the biophysical activity of the endogenous surfactant system $[8,10,32]$. These two different functional states within surfactant metabolism correspond to different surfactant subtypes that can be distinguished morphologically at the electron microscopical level. Using a transmission electron microscopical and stereological approach, active and inactive intraalveolar surfactant subtypes can be analyzed qualitatively and quantitatively in their natural localization and microorganization within the lung. Ultrastructural alterations resembling an increase in the SA/LA ratio have been demonstrated in various forms of acute lung injury [33-35]. A stereological approach has also been used to analyze exogenous surfactant preparations $[36,37]$, but so far, it has not been applied to investigate meconium inhibition of exogenous surfactants.

Therefore, the aim of the present study was to analyze the in vitro effects of meconium and dextran addition on the morphology of a modified porcine natural surfactant (Curosurf) by means of transmission electron microscopy and to quantitate active and inactive subtypes by stereology.

\section{Methods \\ Meconium, surfactant, dextran}

Meconium from 16 healthy term neonates was collected, lyophilised and pooled following parental consent and approval of the study by the local ethics committee. 49.4 $\mathrm{g}$ of the material had a dry weight of $12.2 \mathrm{~g}$ (i.e. water content: $75.3 \%$ ) following lyophylization. For our studies all materials were resuspended/diluted in saline containing $1.5 \mathrm{mmol} / \mathrm{l} \mathrm{CaCl}{ }_{2}$ to reach a meconium concentration of 0.04 or $0.6 \mathrm{mg} / \mathrm{ml}(\mathrm{wt} / \mathrm{vol}$ ), a surfactant (Curosurf, Batch No.: 194/09 original concentration: $80 \mathrm{mg} / \mathrm{ml}$, a kind gift from Nycomed Pharma, Unterschleissheim, Germany) concentration of $10 \mathrm{mg} / \mathrm{ml}$ and a dextran (Dextran T 500 (MW 500,000 Da), Pharmacia LKB, Uppsala, Sweden) concentration of $10 \mathrm{mg} / \mathrm{ml}$ or $20 \mathrm{mg} / \mathrm{ml}$, respectively. For the final experiments the different components were mixed, thereby reaching final concentrations of $2.5 \mathrm{mg} /$ $\mathrm{ml}$ surfactant, 0.02 or $0.3 \mathrm{mg} / \mathrm{ml}$ meconium and 5 or 10 $\mathrm{mg} / \mathrm{ml}$ of dextran, respectively.

\section{Fixation and processing for electron microscopy}

Curosurf samples $(2.5 \mathrm{mg} / \mathrm{ml})$ were either incubated alone or together with meconium or with meconium and dextran for $30 \mathrm{~min}$ at $37^{\circ} \mathrm{C}$ before analysis. Samples containing Curosurf (C), Curosurf + meconium $0.02 \mathrm{mg} / \mathrm{ml}$ (CM0.02), Curosurf + meconium $0.3 \mathrm{mg} / \mathrm{ml}$ (CM0.3), Curosurf + meconium $0.3 \mathrm{mg} / \mathrm{ml}+$ dextran $5 \mathrm{mg} / \mathrm{ml}$ (CM0.3D5), and Curosurf + meconium $0.3 \mathrm{mg} / \mathrm{ml}+$ dextran $10 \mathrm{mg} / \mathrm{ml}$ (CM0.3D10) were fixed and processed for transmission electron microscopy. 
Samples of $0.2 \mathrm{ml}$ were fixed in an equal volume of $1.5 \%$ glutaraldehyde and $1.5 \%$ formaldehyde (made from freshly depolymerized paraformaldehyde) in $0.15 \mathrm{M}$ Hepes buffer, pelleted by centrifugation with a $5417 / \mathrm{R}$ centrifuge (Eppendorf, Hamburg, Germany) at 10,600 g for $10 \mathrm{~min}$, postfixed in $1 \% \mathrm{OsO}_{4}$ in $0.1 \mathrm{M}$ sodium cacodylate, bloc-stained in half-saturated aqueous uranyl acetate over night, dehydrated in an ascending series of acetone and embedded in araldite [see [38]].

Ultrathin sections from 2-3 samples per group were counterstained with lead citrate and analyzed qualitatively and quantitatively at an EM 900 transmission electron microscope (Leo, Oberkochen, Germany) at an accelerating voltage of $50 \mathrm{kV}$.

\section{Stereological analysis}

Volume fractions of surfactant subtypes [lamellar bodylike forms (LBL), multilamellar vesicles (MV), unilamellar vesicles (UV)] were determined stereologically by point counting in systematic uniform random test fields distributed over the whole section. Between 100 and 200 counting events per ultrathin section were generated to ensure that the total observed variability was dominated by the biological variability among samples and not by the variability among stereological measurements within one sample [39].

\section{Surface tension measurements}

Surface tension was determined in vitro using a pulsating bubble [40]surfactometer (Electronetics corporation, Buffalo, New York). In short, a small volume of fluid was transferred into a sample chamber and an air bubble was created. During a $30 \mathrm{sec}$ adsorption period, the surface active material forms a film at the air-liquid interface. Pulsation is started at a frequency of 20 cycles/min by which the bubble undergoes cyclic area compression (50\% of the surface area). Surface tension at minimum bubble size $\left(\gamma_{\min }\right)$ after $5 \mathrm{~min}$ of pulsation at a temperature of $37^{\circ} \mathrm{C}$ is calculated by a computer program from the preset bubble radius and the recorded pressure across the bubble wall making use of the law of Laplace [40].

\section{Results \\ Electron microscopy}

Since the biochemical composition of endogenous surfactant and commercially available exogenous surfactant preparations is different [36], there are also morphological differences between intraalveolar surfactant subtypes and exogenous surfactants. Due to the lack of SP-A, exogenous surfactants do not contain tubular myelin. Other surfactant subtypes, however, were found in Curosurf that can be compared to endogenous surfactant subtypes. Three morphologically different subtypes could be distinguished in Curosurf samples: lamellar body-like forms
(LBL), multilamellar vesicles (MV), and unilamellar vesicles (UV) (Fig. 1A).

All Curosurf-meconium preparations with or without dextran contained LBL, MV and UV, however in varying amounts (Fig. 2A-D). In accordance with previous studies on intraalveolar surfactant ultrastructure [34] and current models of surfactant metabolism [8-10], we classified LBL and MV as LA and UV as SA for subsequent stereological analysis.

\section{Stereology}

The stereological results are summarized in Table 1 and illustrated in Figure 3A. The volume fraction of UV increased with addition of meconium (C: $27 \%$; CM0.02: 34\%; CM0.3: 39\%) and decreased to control values with further addition of dextran (CM0.3D5: 30\%; CM0.3D10: $28 \%)$. Correspondingly, the UV/(LBL+MV) ratio (resembling the SA/LA ratio) increased when meconium was added (C: 0.37; CM0.02: 0.51; CM0.3: 0.65) and decreased to control values when dextran was added to the surfactant-meconium mixture (CM0.3D5: 0.43; CM0.3D10: 0.38).

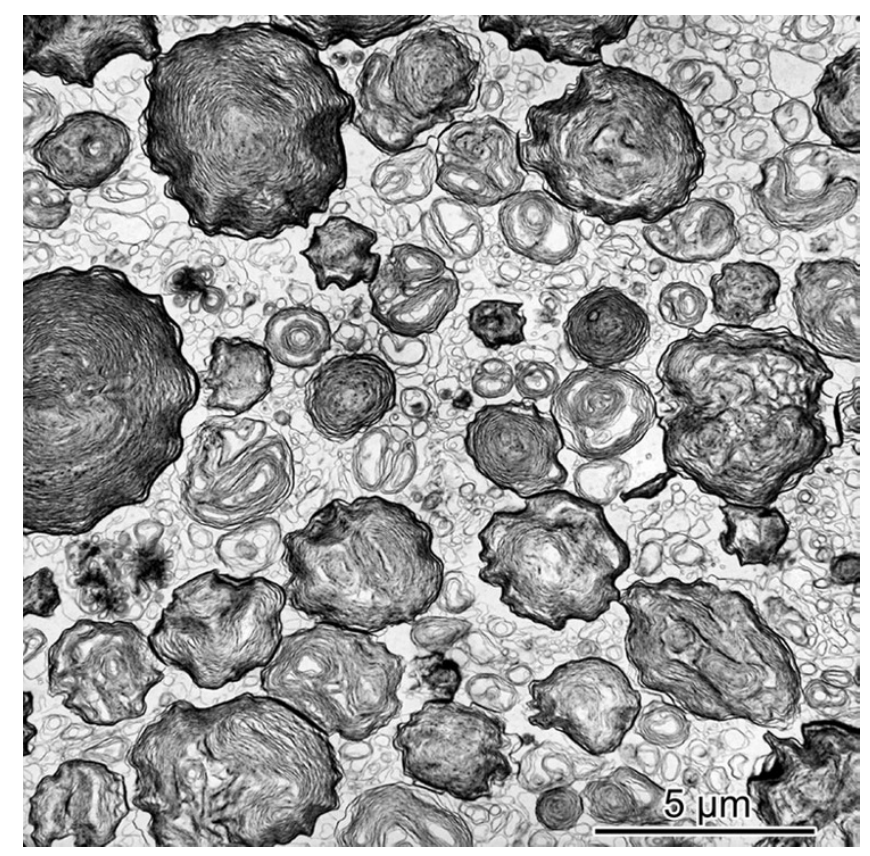

\section{Figure I}

Ultrastructure of Curosurf. Transmission electron micrograph from a pure Curosurf preparation. For details, see Materials and Methods. The preparations are composed of lamellar body-like forms (LBL), multilamellar vesicles (MV), and unilamellar vesicles (UV). 
Table I: Summarized stereological results

\begin{tabular}{lcccc}
\hline Preparation & $\mathrm{V}_{\mathrm{V}}(\mathrm{LBL})[\%]$ & $\mathrm{V}_{\mathrm{V}}(\mathrm{MV})[\%]$ & $\mathrm{V}_{\mathrm{V}}(\mathrm{UV})[\%]$ & $\begin{array}{c}\mathrm{UV} / \\
(\mathrm{LBL}+\mathrm{MV})\end{array}$ \\
\hline C & 26.4 & 46.4 & 27.2 & 0.37 \\
CM0.02 & 33.1 & 33.1 & 33.9 & $0.5 \mathrm{I}$ \\
CM0.3 & 38.0 & 22.7 & 39.2 & 0.65 \\
CM0.3D5 & 42.4 & 27.3 & 30.2 & 0.43 \\
CM0.3DI0 & 43.1 & 29.2 & 27.7 & 0.38 \\
\hline
\end{tabular}

Abbreviations: $V_{V}=$ volume fraction, $L B L=$ lamellar body-like forms, $M V=$ multilamellar vesicles, $U V=$ unilamellar vesicles, $C=$ Curosurf, $M=$ meconium,$D=$ dextran .

\section{Surface tension measurements}

The changes in biophysical activity, as measured by minimum surface tension, are depicted in Figure 3B. Surfactant in the absence of meconium reaches minimum surface tension below $5 \mathrm{mN} / \mathrm{m}$. Addition of meconium inactivates the surface active material and causes an immediate rise in minimum surface tension $>20 \mathrm{mN} / \mathrm{m}$. In parallel to the findings observed in the stereological analysis, the addition of dextran restored the surface activity of Curosurf. This phenomenon could not only be observed following coincubation of Curosurf, meconium and dextran. The addition of dextran to inactivated samples actually reversed the inhibitory effects of meconium in a meconium/surfactant mixture with previously disturbed biophysical function.

\section{Discussion}

The development of exogenous surfactant therapy for the treatment of respiratory distress syndrome (RDS) in premature babies with primary surfactant deficiency is considered one of the major advances in neonatology in our time $[1,41,42]$. Based on this success, the indications for exogenous surfactant therapy have widened to prevent or treat respiratory failure caused by impairment of an originally intact surfactant system like the acute respiratory distress syndrome (ARDS) and other "non-RDS" respiratory disorders $[8,16,19,32,41,43]$. In these cases, however, the efficacy of exogenous surfactant therapy depends largely on the ability of the surfactant preparation to resist the inactivation that caused alterations of the endogenous surfactant system $[1,17,41]$.

The present in vitro study demonstrates that meconium causes alterations in the ultrastructural composition of the modified porcine natural surfactant Curosurf that can be visualized and analyzed qualitatively and quantitatively using transmission electron microscopy and stereological methods. Incubation of Curosurf with increasing concentrations of meconium results in an increase in the volume fraction of unilamellar vesicles and a decrease in the volume fraction of multilamellar vesicles (resembling an increase in the SA/LA ratio), which could be due to rela- tive changes in particle number and/or mean particle size. This ultrastructural finding is paralleled by an increase in minimum surface tension. This demonstrates that the morphological alterations observed in the present in vitro study are relevant to biophysical surfactant function.

An increased SA/LA ratio, as demonstrated by morphological criteria in the present study, is known to be present in various forms of acute lung injury $[8,15,32]$. In general, surfactant can be inactivated by biophysical (e.g. by competition with surfactant lipids at the air-liquid interface) or biochemical (e.g. by enzymatic degradation) mechanisms. In meconium-induced surfactant inactivation, inhibitors of surfactant function like plasma proteins [4]or bilirubin [44] seem to be involved [18,19,43]. Meconium also contains secreted phospholipase $\mathrm{A}_{2}$ [45], so that enzymatic degradation of lipids and proteins is another inhibitory mechanism to be discussed. Recently, Kakinuma et al. reported an accelerated subtype conversion as an additional mechanism for meconium-induced surfactant inactivation [15], indicating that also the sensitive interaction between surfactant lipids and proteins that is needed for the formation of the surface active film can be disturbed by meconium.

The mechanisms by which dextran counteracts the inhibitory effects of meconium on surfactant function are as yet unclear [24]. It is possible that the addition of hydrophilic polymers lowers the energy barrier to surfactant adsorption via a nonspecific depletion attraction [46]. In our study, dextran prevents an increased conversion of LA to SA, thereby exhibiting a protective/stabilising effect on LA. A similar function has been described in vivo for SP-A $[47,48]$. Moreover, SP-A inhibits surfactant phospholipid hydrolysis by secreted phospholipase $\mathrm{A}_{2}$ [49]. The idea to look for functional analogues for the carbohydrate binding domain of SP-A prompted Taeusch et al. to study the effects of other "sugars", including dextran, on the resistance of surfactant towards inhibitors [24]. For the currently available exogenous surfactant preparations that do not contain SP-A, dextran might be a useful addition in order to improve the maintainance of the structural and functional integrity of surface active subtypes. Curosurf also contains relatively little $(\approx 1 \%)$ of SP-B and SP-C. As surfactant subtype conversion has also been shown to be related to loss of SP-B and surface activity in LA [5], this might explain why natural modified surfactants that are extracted from lung homogenate/lung lavage fluid with organic solvents are more prone to inhibition than "native" surfactant from amniotic fluid or lung lavage fluid [22]. In this respect, the development of new "designer surfactants" [21,50]with increased resistance to inactivation seems necessary for a more successful exogenous surfactant treatment of ARDS and related disorders like meconium aspiration syndrome. Such surfactants 

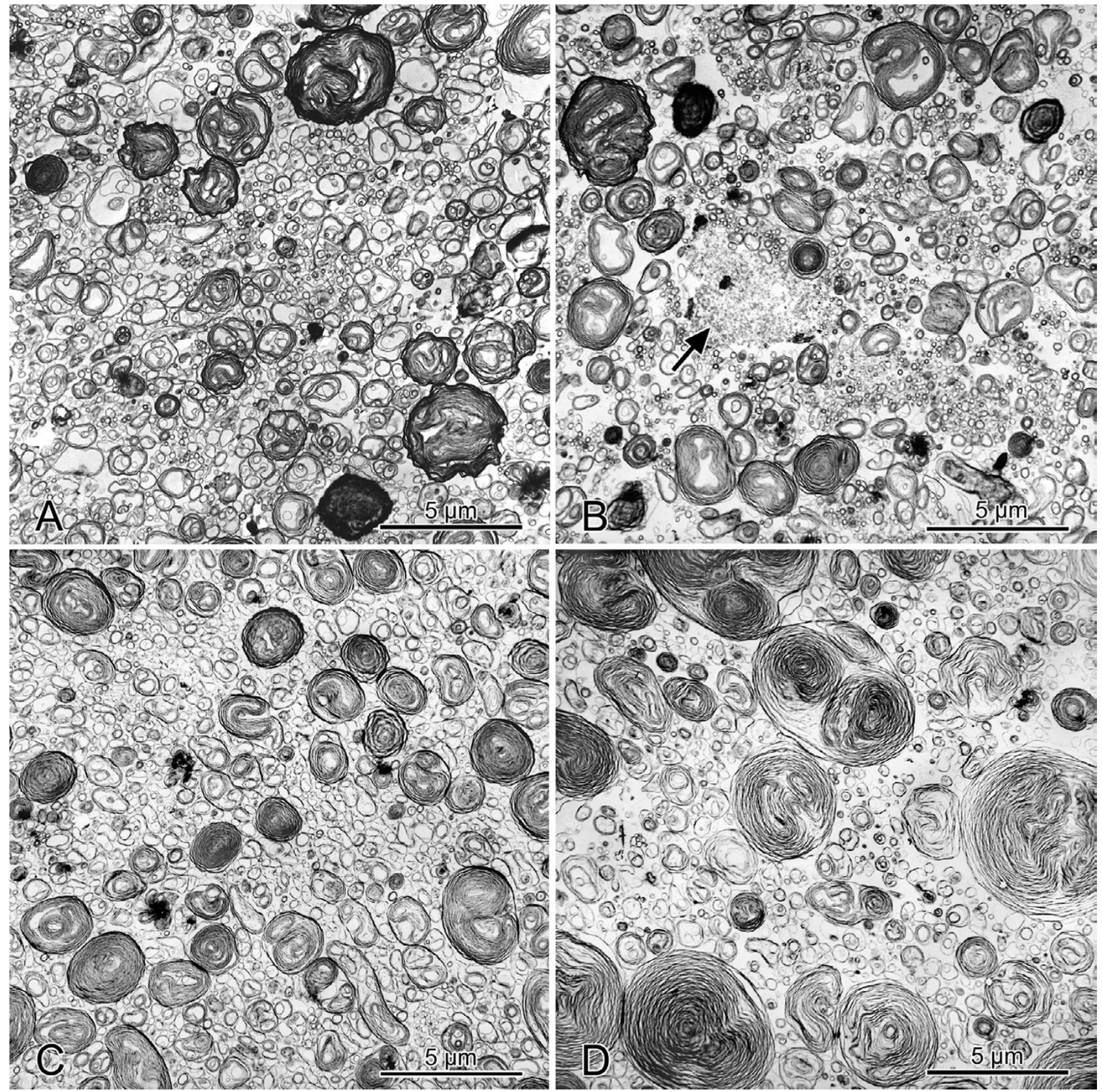

\section{Figure 2}

Ultrastructure of Curosurf, meconium, and dextran. Transmission electron micrographs from Curosurf preparations after incubation with $0.02 \mathrm{mg} / \mathrm{ml}$ meconium $(\mathbf{A}), 0.3 \mathrm{mg} / \mathrm{ml}$ meconium $(\mathbf{B}), 0.3 \mathrm{mg} / \mathrm{ml}$ meconium $+5 \mathrm{mg} / \mathrm{ml} \mathrm{dextran}(\mathbf{C})$, and $0.3 \mathrm{mg} / \mathrm{ml}$ meconium + $10 \mathrm{mg} / \mathrm{ml}$ dextran (D). With increasing concentrations of meconium, more unilamellar vesicles become visible (A and $\mathbf{B})$. The flocculent material visible in the center of $\mathbf{B}$ most likely represents meconium material (arrow). The addition of increasing concentrations of dextran leads to more lamellar body like forms and less unilamellar vesicles (C and $\mathbf{D})$.

with recombinant proteins or peptide analogues of the surfactant apoproteins will be relatively expensive to produce. Dextran is cheap and it is easy to mix with surfactant. However, there is indication from animal work that the effects of dextran in vivo differ between various surfactants. In addition, dextran, due to its high osmolality, bears the risk of fluid accumulation in the lung, so that alternatives like polyethylene glycol [30], hyaluronic acid 

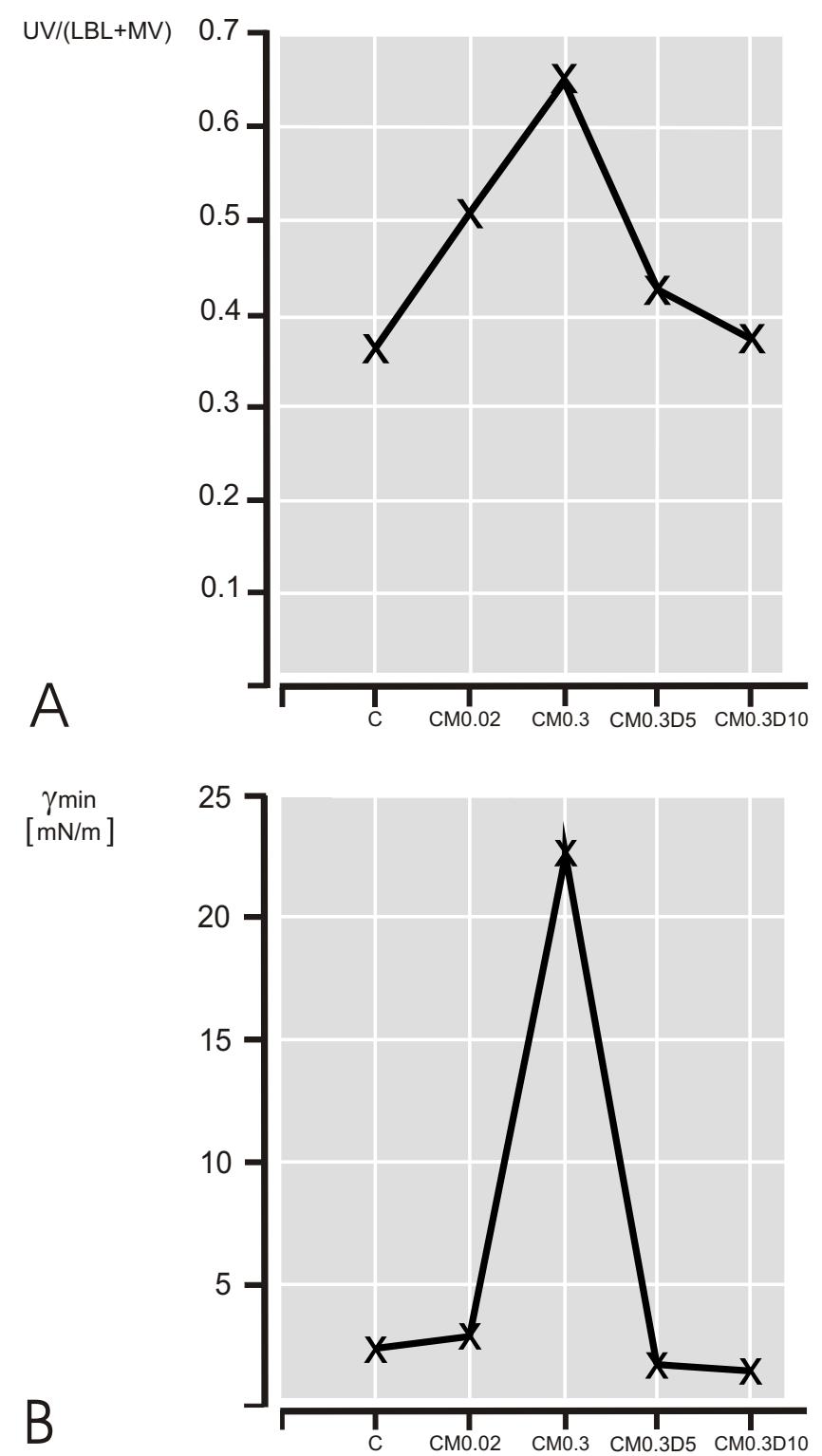

\section{Figure 3}

Stereology versus minimum surface tension. A: Ratio of unilamellar vesicles to lamellar body-like forms and multilamellar vesicles, used as a morphological correlate to the small to large aggregate ratio. Samples contained Curosurf (C), Curosurf + meconium $0.02 \mathrm{mg} / \mathrm{ml}$ (CM0.02), Curosurf + meconium $0.3 \mathrm{mg} / \mathrm{ml}$ (CM0.3), Curosurf + meconium $0.3 \mathrm{mg} /$ $\mathrm{ml}+$ dextran $5 \mathrm{mg} / \mathrm{ml}$ (CM0.3D5), and Curosurf + meconium $0.3 \mathrm{mg} / \mathrm{ml}+$ dextran $10 \mathrm{mg} / \mathrm{ml}$ (CM0.3D I0). B: Minimum surface tension of Curosurf, Curosurf/meconium- and Curosurf/ meconium/dextran-mixtures as measured after 5 min of cyclic area changes in the pulsating bubble surfactometer. Values are means from 5 repeated measurements.
[30,51] or polymyxin B [52]are currently being investigated. The technique presented in our investigation might be useful for such studies as well.

\section{Conclusion}

In conclusion, meconium causes alterations in the ultrastructural composition of the natural modified surfactant Curosurf that can be visualized and analyzed by TEM and stereology. These alterations resemble an increased SA/LA ratio, indicating that an increased conversion of surface active forms to inactive forms is involved in the pathomechanism of meconium-induced surfactant inactivation. These morphological alterations are paralleled by an increase in minimum surface tension. Dextran prevents these alterations and may therefore be a useful additive to exogenous surfactant preparations to preserve or reconstitute their structural and functional integrity, thereby improving their resistance to inactivation.

\section{Competing interests}

The author(s) declare that they have no competing interests.

\section{Authors' contributions}

$\mathrm{MO}$ conceived of and participated in the design of the study, carried out the transmission electron microscopic studies, supervised the stereological analysis, and drafted the manuscript. MS carried out the stereological analysis. GS mixed the components, carried out the surface tension measurements, and participated in the drafting of the manuscript. EH conceived of and participated in the design of the study, supervised the surface tension measurements, and participated in the drafting of the manuscript. All authors read and approved the final manuscript.

\section{Acknowledgements}

We are grateful to the parents, midwives and nurses of the Department of Obstetrics and Gynecology at the University of Göttingen for collection of the meconium. The authors thank S. Freese, A. Gerken, H. Hühn, S. Wienstroth, and G. Walter for expert technical assistance. M.O. acknowledges financial support by government authorities (BMBF and NMWK) and the German Research Council (DFG Oc 23/8-I). E.H. was supported by a grant of the German Research Council (DFG He 2072/2-2). Parts of this work have been presented at the 18th International Workshop on Surfactant Replacement, Prague, 2003.

\section{References}

I. Notter RH: Lung surfactants. Basic science and clinical applications. Lung biology in health and disease Volume 149. New York: Marcel Dekker; 2000.

2. McCormack FX, Whitsett JA: The pulmonary collectins, SP-A and SP-D, orchestrate innate immunity in the lung. J Clin Invest 2002, 109:707-7/2.

3. Wright JR: Pulmonary surfactant: a front line of lung host defense. J Clin Invest 2003, I I I: | 1453- | 455.

4. Seeger W, Grube C, Günther A, Schmidt R: Surfactant inhibition by plasma proteins: differential sensitivity of various surfactant preparations. Eur Respir J 1993, 6:97| I-977. 
5. Günther A, Schmidt R, Feustel A, Meier U, Pucker C, Ermert M, Seeger W: Surfactant subtype conversion is related to loss of surfactant apoprotein $B$ and surface activity in large surfactant aggregates. Am J Respir Crit Care Med 1999, I 59:244-25I.

6. Hawgood S: Surfactant: composition, structure, and metabolism. In The lung. Scientific foundations 2 nd edition. Edited by: Crystal RG, West JB, Weibel ER, Barnes PJ. Philadelphia:Lippincott-Raven; | 1997:557-57I.

7. Ochs M, Johnen G, Müller KM, Wahlers T, Hawgood S, Richter J, Brasch F: Intracellular and intraalveolar localization of surfactant protein A (SP-A) in the parenchymal region of the human lung. Am J Respir Cell Mol Biol 2002, 26:91-98.

8. Lewis JF, Novick RJ, Veldhuizen RAW: Surfactant in lung injury and lung transplantation Austin: RG Landes; 1997.

9. Ikegami M, Jobe AH: Surfactant protein metabolism in vivo. Biochim Biophys Acta 1998, I 408:2 18-225.

10. Günther A, Ruppert C, Schmidt R, Markart P, Grimminger F, Walmrath D, Seeger W: Surfactant alteration and replacement in acute respiratory distress syndrome. Respir Res 200I, 2:353-364

II. Clark DA, Nieman GF, Thompson JE, Paskanik AM, Rokhar JE, Bredenberg CE: Surfactant displacement by meconium free fatty acids: an alternative explanation for atelectasis in meconium aspiration syndrome. J Pediatr 1987, 1 1 0:765-770.

12. Moses D, Holm BA, Spitale P, Liu MY, Enhorning G: Inhibition of pulmonary surfactant function by meconium. Am J Obstet Gynecol 1991, 164:477-481.

13. Sun B, Curstedt T, Robertson B: Surfactant inhibition in experimental meconium aspiration. Acta Paediatr 1993, 82:182-189.

14. Cleary GM, Antunes MJ, Ciesielka DA, Higgins ST, Spitzer AR, Chan$\operatorname{der} A$ : Exudative lung injury is associated with decreased levels of surfactant proteins in a rat model of meconium aspiration. Pediatrics 1997, 100:998-1003.

15. Kakinuma R, Shimizu H, Ogawa Y: Effect of meconium on the rate of in vitro subtype conversion of swine pulmonary surfactant. Eur J Pediatr 2002, 161:31-36.

16. Walther FJ: Surfactant therapy for neonatal lung disorders other than respiratory distress syndrome. In Surfactant therapy for lung disease. Lung biology in health and disease Volume 84. Edited by: Robertson B, Taeusch HW. New York: Marcel Dekker; 1995:46I-476.

17. Robertson B, Johansson J, Curstedt T: Synthetic surfactants to treat neonatal lung disease. Mol Med Today 2000, 6: I 19-124.

18. Taeusch HW: Treatment of acute (adult) respiratory distress syndrome. The holy grail of surfactant therapy. Biol Neonate 2000, 77(suppl I):2-8.

19. Wiswell TE: Expanded uses of surfactant therapy. Clinics Perinatol 200I, 28:695-7II.

20. Curley $A E$, Halliday HL: The present status of exogenous surfactant for the newborn. Early Hum Dev 200I, 61:67-83.

21. Merrill JD, Ballard RA: Pulmonary surfactant for neonatal respiratory disorders. Curr Opin Pediatr 2003, I5:| $49-154$.

22. Herting E, Rauprich P, Stichtenoth G, Walter G, Johansson J, Robertson $B$ : Resistance of different surfactant preparations to inactivation by meconium. Pediatr Res 200I, 50:44-49.

23. Bae CW, Takahashi A, Chida S, Sasaki M: Morphology and function of pulmonary surfactant inhibited by meconium. Pediatr Res 1998, 44:|87-|9|.

24. Taeusch HW, Lu KW, Goerke J, Clements JA: Nonionic polymers reverse inactivation of surfactant by meconium and other substances. Am J Respir Crit Care Med 1999, 159:1391-1395.

25. Tashiro K, Kobayashi T, Robertson B: Dextran reduces surfactant inhibition by meconium. Acta Paediatr 2000, 89: I439-I 445.

26. Tashiro K, Cui XG, Kobayashi T, Curstedt T, Robertson B: Modified protocols for surfactant therapy in experimental meconium aspiration syndrome. Biol Neonate 2003, 83:49-56.

27. Kobayashi T, Ohta K, Tashiro K, Nishizuka K, Chen WM, Ohmura S, Yamamoto K: Dextran restores albumin-inhibited surface activity of pulmonary surfactant. J Appl Physiol 1999, 86:1778-1784

28. Lu JJ, Cheung WWY, Yu LMY, Policova Z, Li D, Hair ML, Neumann AW: The effect of dextran to restore the activity of pulmonary surfactant inhibited by albumin. Respir Physiol Neurobiol 2002, 130:169-179.

29. Cui XG, Tashiro K, Matsumoto H, Tsubokawa Y, Kobayashi T: Aerosolized surfactant and dextran for experimental acute res- piratory distress syndrome caused by acidified milk in rats. Acta Anaesthesiol Scand 2003, 47:853-860.

30. Taeusch HW, de la Serna JB, Perez-Gil J, Alonso C, Zasadzinski JA: Inhibition of pulmonary surfactant adsorption by serum and the mechanisms of reversal by hydrophilic polymers: experimental. Biophys J 2005, 89: I769-1779.

31. Dargaville PA, Morley C]: Overcoming surfactant inhibition with polymers. Acta Paediatr 2000, 89:1397-1400.

32. Lewis JF, Veldhuizen R: The role of exogenous surfactant in the treatment of acute lung injury. Annu Rev Physiol 2003, 65:613-642.

33. Fehrenbach $\mathrm{H}$, Brasch F, Uhlig S, Weisser M, Stamme C, Wendel A Richter J: Early alterations in intracellular and alveolar surfactant of the rat lung in response to endotoxin. Am J Respir Crit Care Med 1998, 157:1630-1639.

34. Ochs M, Nenadic I, Fehrenbach A, Albes JM, Wahlers T, Richter J, Fehrenbach $\mathrm{H}$ : Ultrastructural alterations in intraalveolar surfactant subtypes after experimental ischemia and reperfusion. Am J Respir Crit Care Med 1999, 160:718-724.

35. Ochs M, Fehrenbach H, Nenadic I, Bando T, Fehrenbach A, Schepelmann D, Albes JM, Wahlers T, Richter J: Preservation of intraalveolar surfactant in a rat lung ischaemia/reperfusion injury model. Eur Respir J 2000, 15:526-531.

36. Bernhard W, Mottaghian J, Gebert A, Rau GA, von der Hardt H, Poets CF: Commercial versus native surfactants. Surface activity, molecular components, and the effect of calcium. Am J Respir Crit Care Med 2000, 162:1524-1533.

37. Schmiedl A, Krug N, Hohlfeld JM: Influence of plasma and inflammatory proteins on the ultrastructure of exogenous surfactant. J Electron Microsc 2004, 53:407-4I6.

38. Fehrenbach $\mathrm{H}$, Ochs $\mathrm{M}$ : Studying lung ultrastructure. In Methods in pulmonary research Edited by: Uhlig S, Taylor AE. Basel: Birkhäuser; 1998:429-454

39. Howard CV, Reed MG: Unbiased stereology. Three-dimensional measurement in microscopy 2nd edition. Oxford: Bios; 2005.

40. Enhorning G: Pulsating bubble technique for evaluating pulmonary surfactant. J Appl Physiol 1977, 43:198-203.

41. Robertson B, Taeusch HW, (Eds): Surfactant therapy for lung disease. Lung biology in health and disease Volume 84. New York: Marcel Dekker; 1995

42. Clements JA, Avery ME: Lung surfactant and neonatal respiratory distress syndrome. Am J Respir Crit Care Med 1998, I57:S59-S66

43. Greenough A: Expanded uses of surfactant replacement therapy. Eur J Pediatr 2000, 159:635-640.

44. Amato M, Schürch S, Grunder R, Bachofen H, Burri P: Influence of bilirubin on surface tension properties of lung surfactant. Arch Dis Child 1996, 75:FI9I-FI96.

45. Schrama AJJ, de Beaufort AJ, Sukul YRM, Jansen SM, Poorthuis BJHM, Berger HM: Phospholipase $A_{2}$ is present in meconium and inhibits the activity of pulmonary surfactant: an in vitro study. Acta Paediatr 200I, 90:4I2-4I6.

46. Zasadzinski JA, Alig TF, Alonso C, de la Serna JB, Perez-Gil J, Taeusch $\mathrm{HW}$ : Inhibition of pulmonary surfactant adsorption by serum and the mechanisms of reversal by hydrophilic polymers: theory. Biophys / 2005, 89:1621-1629.

47. Yukitake K, Brown CL, Schlueter MA, Clements JA, Hawgood S: Surfactant apoprotein A modifies the inhibitory effect of plasma proteins on surfactant activity in vivo. Pediatr Res 1995, 37:21-25.

48. Strayer DS, Herting E, Sun B, Robertson B: Antibody to surfactant protein $A$ increases sensitivity of pulmonary surfactant to inactivation by fibrinogen in vivo. Am J Respir Crit Care Med 1996, 153:1116-1122.

49. Chabot S, Koumanov K, Lambeau G, Gelb MH, Balloy V, Chignard M, Whitsett JA, Touqui L: Inhibitory effects of surfactant protein A on surfactant phospholipid hydrolysis by secreted phospholipases A $_{2}$. J Immunol 2003, I 71:995-1000.

50. Holm BA, Waring AJ: Designer surfactants. The next generation in surfactant replacement. Clinics Perinatol 1993 , 20:813-829.

51. Lu KW, Goerke J, Clements JA, Taeusch HW: Hyaluronan reduces surfactant inhibition and improves rat lung function after meconium injury. Pediatr Res 2005, 58:206-210.

52. Stichtenoth G, Jung P, Walter G, Johansson J, Robertson B, Curstedt $\mathrm{T}$, Herting E: Polymyxin B/pulmonary surfactant mixtures 
have increased resistance to inactivation by meconium and reduce growth of gram-negative bacteria in vitro. Pediatr Res 2006, 59:407-4II.

Publish with Bio Med Central and every scientist can read your work free of charge

"BioMed Central will be the most significant development for disseminating the results of biomedical research in our lifetime. " Sir Paul Nurse, Cancer Research UK

Your research papers will be:

- available free of charge to the entire biomedical community

- peer reviewed and published immediately upon acceptance

- cited in PubMed and archived on PubMed Central

- yours - you keep the copyright

Submit your manuscript here:

http://www.biomedcentral.com/info/publishing_adv.asp 